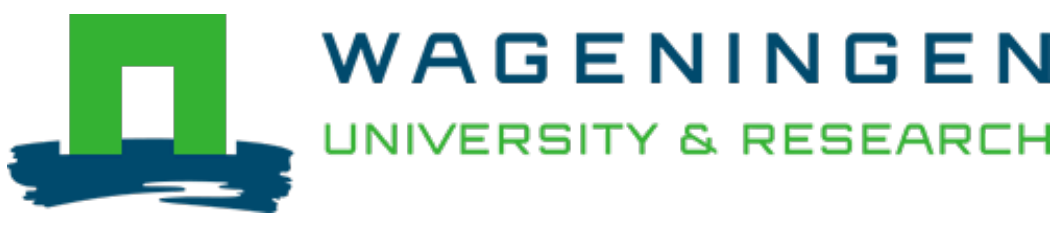

\author{
Analysis of high frequency photovoltaic solar energy fluctuations \\ Solar Energy \\ Kreuwel, Frank P.M.; Knap, Wouter H.; Visser, Lennard R.; Sark, Wilfried G.J.H.M.; Vilà-Guerau de \\ Arellano, Jordi et al \\ https://doi.org/10.1016/j.solener.2020.05.093
}

This article is made publicly available in the institutional repository of Wageningen University and Research, under the terms of article $25 \mathrm{fa}$ of the Dutch Copyright Act, also known as the Amendment Taverne. This has been done with explicit consent by the author.

Article $25 \mathrm{fa}$ states that the author of a short scientific work funded either wholly or partially by Dutch public funds is entitled to make that work publicly available for no consideration following a reasonable period of time after the work was first published, provided that clear reference is made to the source of the first publication of the work.

This publication is distributed under The Association of Universities in the Netherlands (VSNU) 'Article $25 \mathrm{fa}$ implementation' project. In this project research outputs of researchers employed by Dutch Universities that comply with the legal requirements of Article $25 \mathrm{fa}$ of the Dutch Copyright Act are distributed online and free of cost or other barriers in institutional repositories. Research outputs are distributed six months after their first online publication in the original published version and with proper attribution to the source of the original publication.

You are permitted to download and use the publication for personal purposes. All rights remain with the author(s) and / or copyright owner(s) of this work. Any use of the publication or parts of it other than authorised under article $25 \mathrm{fa}$ of the Dutch Copyright act is prohibited. Wageningen University \& Research and the author(s) of this publication shall not be held responsible or liable for any damages resulting from your (re)use of this publication.

For questions regarding the public availability of this article please contact openscience.library@wur.nl 


\title{
Analysis of high frequency photovoltaic solar energy fluctuations
}

\author{
Frank P.M. Kreuwel ${ }^{\mathrm{a}, \mathrm{b}, *}$, Wouter H. Knap ${ }^{\mathrm{c}}$, Lennard R. Visser ${ }^{\mathrm{d}}$, Wilfried G.J.H.M. van Sark ${ }^{\mathrm{d}}$, \\ Jordi Vilà-Guerau de Arellano $^{\mathrm{a}}$, Chiel C. van Heerwaarden ${ }^{\mathrm{a}}$ \\ ${ }^{a}$ Meteorology and Air Quality Group, Wageningen University \& Research, P.O. Box 47, 6700 AA Wageningen, the Netherlands \\ ${ }^{\mathrm{b}}$ Alliander N.V., P.O. Box 50, 6920 AB Duiven, the Netherlands \\ ${ }^{\mathrm{c}}$ Royal Netherlands Meteorological Institute, P.O. Box 201, 3730 AE De Bilt, the Netherlands \\ ${ }^{\mathrm{d}}$ Utrecht University, Copernicus Institute of Sustainable Development, Princetonplein 8A, 3584 CB Utrecht, the Netherlands
}

\section{A R T I C L E I N F O}

\section{Keywords:}

Solar power fluctuations

Temporal averaging

Cloud enhancement

PV

PV grid integration

BSRN

\begin{abstract}
A B S T R A C T
Characterizing short-term variability of generated solar power is important for the integration of photovoltaic (PV) systems into the electrical grid. Using different kinds of high frequency, in-situ observations of both irradiance and generated PV power, we quantify insights on temporal averaging effects on the highest observed peaks and ramp rates, which closely relate to grid stability. We use measurements obtained at three specific spatial scales; a single point pyranometer, two household PV systems and a PV system typical for small medium businesses. We show that the 15-minute time resolution typically used for grid calculations significantly underestimates key dynamics at high temporal resolutions, such as ramp rates and maximum power output, at the local grid level. We find that absolute power peaks in the order of seconds are up to $18 \%$ higher compared to a 15-minute resolution for irradiance and up to $22 \%$ higher for a household PV system. For the largest PV system, the increase is limited to $11 \%$. Furthermore, we find that the highest peaks solely occur under mixed-cloud conditions. Additionally, we show that the time interval-dependency of the largest power ramps is similar for all systems under research, ranging from $\sim 20 \%$ at a 5-second interval to stabilizing at $70-80 \%$ between 5 and $10 \mathrm{~min}$, which we can explain based on meteorological arguments.
\end{abstract}

\section{Introduction}

The worldwide installed capacity of photovoltaic (PV) solar energy systems is anticipated to multiply over tenfold in the next decade, from 486 GWp in 2018 (International Renewable Energy Agency, 2019) up to between 3 and 10 TWp in 2030 (Haegel et al., 2017). As penetration levels of photovoltaics increase, weather-induced variability in power output of PV systems has a greater impact on the electricity grid. This can negatively impact utility grid stability by affecting grid voltage and frequency (Tan and Kirschen, 2007), requiring additional regulation (Stetz et al., 2015). Because energy generation from renewable resources is highly unpredictable, grid operators design their grids for extreme power outputs such as in the case of clear sky condition.

At present, operational calculations used for grid design are limited to a temporal resolution in the order of 5 to $15 \mathrm{~min}$ (Sande et al., 2017). However, variability of solar energy due to cloud shading occurs at very short timescales, in the order of 1 s (Lohmann and Monahan 2018). Considering the typically used, coarser timescales the frequency and amplitude of high-frequency power fluctuations is flattened due to time averaging. Additionally, at short timescales cloud enhancement can lead to irradiance exceeding clear-sky conditions (Gueymard 2017), resulting in an increased PV power output, possibly causing grid voltages to exceed safety limits (Mills et al., 2011; Shah et al., 2015), depending on inverter clipping or preset curtailment levels (Tonkoski and Lopes 2011).

High-frequency fluctuations of PV power output are mainly driven by fluctuations of irradiance. While the variability of irradiance (Kleissl and Lave 2013, Lohmann et al., 2016, Lohmann 2018) as well as the power fluctuations of large solar parks (Perez and Hoff 2010; Marcos et al., 2011; van Haaren et al., 2014) has been well studied, the effect on relatively small but abundant household PV systems remains poorly understood. It is anticipated that in the near future a significant part of the installed PV capacity will originate from these relatively smaller PV systems, typical for rooftops of homes and businesses (Šúri et al., 2017).

Up to this moment, research aimed at understanding the power variability of these type of PV systems has been limited to coarse temporal resolutions in the order of $10 \mathrm{~min}$ or relied on estimating PV output power from derived irradiance observations (Widén et al., 2010, Hansen et al., 2012a, Hansen et al., 2012b, Anvari et al., 2016). Moreover, studies on irradiance typically concern the horizontal plane,

\footnotetext{
* Corresponding author.

E-mail address: frank.kreuwel@alliander.com (F.P.M. Kreuwel).
} 
whereas PV system are commonly tilted and irradiance variability on the inclined plane is known to be greater than on the horizontal due to a larger fraction of direct irradiance (Suri et al., 2007).

Additionally, the efficiency of solar panels depends on the temperature of the solar cells in the panels (Skoplaki and Palyvos 2009), whereas irradiance measurements do not have this temperature dependency. Due to the thermal capacity of the solar panels, broken-cloud conditions compared to clear-sky conditions can temporally lead to lower cell temperatures resulting in a higher conversion and thus a higher output power (Jones and Underwood 2001). As Jones and Underwood found, the thermal response of a typical panel is in the order of 7 min, which is much larger than the timescales on which high-frequency fluctuations dominate. Although the effect of irradiance on the temperature of PV modules has been described in literature (Armstrong and Hurley 2010, Tsai and Tsai 2012, Lobera and Valkealahti 2013), this has not been connected to high-yield extremes observed at PV systems.

To enable large-scale integration of distributed and small-scale PV systems in the electricity grid and contain the risks of power output peaks and possibly power outages, a better understanding is required of the variability of generated solar power by a single or fleet of such systems and how this can be connected to existing meteorological knowledge of weather-induced irradiance fluctuations.

In this paper we present direct measurements of high frequency fluctuations in power output of PV systems and radiation observations. We show that these high frequency fluctuations have a profound impact on power output peaks in the electricity grid. We discuss how the physical behavior of these PV systems poses significant challenges for power grid design. Moreover, we relate the behavior of the household PV systems to the better understood weather-induced variability of irradiance and larger PV systems, typical for small to medium enterprises (SMEs).

Aiming to deliver insights ready for use by the utility sector, we examine commonly observable extreme values of two parameters as a function of time averaging interval, i.e., the maximum power and the maximum ramp rate. These parameters are closely linked to two aspects of grid stability: peak voltage limits and power-line flicker.

The rest of this paper is organized as follows. Section 2 presents the definitions used throughout this work, and a description of the measurement set ups. In Section 3, we present and analyze the effect of time-averaging high-frequency observations for the systems under investigation. Finally, the work is concluded and the impact of the findings presented in this work is discussed in Section 4.

\section{Method}

\subsection{Definitions}

To quantify the impact of high frequency fluctuations on power peaks, we consider two variables in detail: the maximum instantaneous power $P_{\max }$ and maximum instantaneous ramp rate $\Delta P_{\max }$ at a specific time resolution $\tau$. In order to not let the results be impacted by a single high-value event, we analyze the 99.7th percentile of a given parameter as the maximum value ( $R_{99.7}$, corresponding to $3 \sigma$ ), as we regard this to represent the commonly observable extreme. The expressions of these high frequency indicators read:

$P_{\max }(\tau) \equiv \mathrm{R}_{99.7}(P(\tau))$

$\Delta P_{\max }(\tau)=\mathrm{R}_{99.7}(P(\tau+1)-P(\tau))$

where time averaged power $P(\tau)$ over time interval $\tau$ is defined by:

$P(\tau)=\frac{\int_{\tau} P(t) d t}{\tau}$

To compare maximum power peaks and ramp rates between systems, we normalize each of the four datasets to the observed maximum power at a 15-minute time interval as this interval is the default time resolution of the energy industry:

$P_{o b s} \equiv P_{\max }(15 \mathrm{~min})$

\subsection{Measurement set ups}

In this research we combine high-resolution measurement data from four set-ups: global horizontal irradiance, two household PV systems and an SME PV system measured with response times of 5, 2, 2 and $1 \mathrm{~s}$, respectively. The set ups are located within a $40 \mathrm{~km}$ radius near the center of the Netherlands.

The measurements of all systems where obtained between July 8th and September 1st. The households PV systems where measured in 2015 whereas irradiance and the SME PV system were measured in 2018. Year-to-year variations of irradiance can be significant (Tonkoski and Lopes 2011), therefore this work is limited to comparisons of statistical parameters on timescales where the impact of year-to-year variations on the results is small. Furthermore, these statistical parameters do not require the systems to be on the same location.

\subsubsection{BSRN irradiance measurement}

Global horizontal irradiance is measured using a class A thermopile CMP22 Kipp \& Zonen Pyranometer, classification to ISO 9060:2018 Spectrally Flat Class A (Kipp and Zonen, 2019). The set up is part of the Baseline Surface Radiation Network (BSRN) (Driemel, et al. 2018). For the BSRN station we consider here the data is stored at $1 \mathrm{~Hz}$. High temporal resolution storage is not required by BSRN, the central BSRN database stores $1 \mathrm{~min}$ values, but is highly recommened for e.g. PV applications. Since the $95 \%$ response time of the device is $5 \mathrm{~s}$, this is used as the highest temporal resolution. Calibration of the device can be directly linked to the World Radiometric Reference (World Meteorological Organization 2016). The system is located in Cabauw, the Netherlands $\left(51^{\circ} 58^{\prime} 13^{\prime \prime} \mathrm{N}, 4^{\circ} 55^{\prime} 35^{\prime \prime} \mathrm{E}\right)$ and maintained by the Royal Netherlands Meteorological Institute (Knap 2015). Using Eq. (4), we find a $P_{o b s}$ of $0.87 \mathrm{~kW}$, per $\mathrm{m}^{2}$ of sensor surface.

\subsubsection{Household PV systems}

Two rooftop PV systems, comprised of c-Si panels, are connected with power measurement data loggers (Upp Energy, 2013), as part of a larger PV system network (Elsinga and van Sark 2017). The power data is recorded at a resolution of $0.7 \mathrm{~W}$ and stored at $0.5 \mathrm{~Hz}$. A summary of the technical details is given in Table 1 . The two systems are oriented due south at an inclination of $47^{\circ}$ and $40^{\circ}$ and show a $P_{\text {obs }}$ of $2.0 \mathrm{~kW}$ and $2.9 \mathrm{~kW}$ respectively. The inverter of the $2.9 \mathrm{~kW}$ household system has a rated AC power of $2.6 \mathrm{~kW}$ (Samil Power Co, Ltd, 2016), thereby limiting the maximum output power of the system, even without cloud enhancement. The $2.9 \mathrm{~kW}$ system will be referred to as the inverter limited' system. With a capacity of $2.3 \mathrm{~kW}$ the inverter of the second PV system does not limit the power production. Both systems are located in the city of Utrecht, the Netherlands $\left(52^{\circ} 05^{\prime} \mathrm{N} 5^{\circ} 06^{\prime} \mathrm{E}\right)$.

\subsubsection{SME PV system}

The SME PV system is comprised of 442c-Si solar panels with a nominal capacity of $245 \mathrm{Wp}$, arranged in a $17 \times 26$ panel grid, devided into 6 subsections with a 3-phase inverter each. A summary of the technical details is given in Table 1 , where the inverter rated AC power is the sum of the individual inverters. A remote terminal unit measures the generated current per phase at $1 \mathrm{~Hz}$ using three LEM RT 500 Rogowski coils (LEM 2014) on the low-voltage cable at the secondary substation located approximately $60 \mathrm{~m}$ from the PV system. The generated current is nearly identical for the three phases, as all inverters feed into each of the phases. Therefore, the generated power is calculated for one of the measured phases for which also the voltage is measured directly. In this research we will only refer to the generated power on the single phase, with $P_{o b s}$ of $27 \mathrm{~kW}$. The system is located 
above a parking lot on an industrial area near the city of Duiven, the Netherlands $\left(51^{\circ} 58^{\prime} \mathrm{N}, 5^{\circ} 59^{\prime} \mathrm{E}\right)$.

\subsection{Data preparation}

All time series were prepared following the same procedure. First, each dataset was resampled to exactly match its recording frequency. This is done by taking the average if multiple values were recorded in one interval, or linearly interpolating missing values, up to a limit of 5 subsequent missing values. Time intervals with a greater sparsity of observations are omitted from further analyses. Second, days with $<$ 95\% of the expected data points between 08:00 and 16:00 UTC were omitted. In total, 56 days of the irradiance and inverter limited PV system were suitable, 54 days of the SME PV system and 39 days of the other household PV system.

\subsection{Classification scheme}

The weather conditions found on a certain day, e.g. overcast, clear sky or mixed, influence the maximum power output and ramp rate observed on that day. Moreover, due to cloud enhancement temporary extreme power output can be observed compared to clear sky conditions (Gueymard 2017). To allow for comparison of these results for different types of days, we categorize each day according to an adaptation of an earlier proposed classification based on Daily Clearness Index (DCI) and Variability Index (VI) (Stein, Hansen and Reno 2012). Instead of DCI, which requires a parametrization of clear-sky irradiance, we consider the surface integral (S) of the irradiance or PV energy yield, which represents the total energy. Secondly, we normalize VI to the day with the highest observed variability for each dataset: $\mathrm{VI}_{\mathrm{n}}$. We then define four classes of days as follows:

- Highly variable; The 10 days with highest $\mathrm{VI}_{\mathrm{n}}$ - High yield;

$$
\mathrm{VI}_{\mathrm{n}}<0.2 \& \mathrm{~S}>2 / 3 * \max (\mathrm{S})+1 / 3 * \min (\mathrm{S})
$$

- Low yield;

$$
\mathrm{VI}_{\mathrm{n}}<0.2 \& \mathrm{~S}<1 / 3 * \max (\mathrm{S})+2 / 3^{*} \min (\mathrm{S})
$$

- Mixed conditions;

All other days, they are included in our analysis

\section{Results}

\subsection{Fluctuations in detail}

Differences between data with high and low temporal resolution are most significant when fluctuations occur, e.g. during cloud to clear-sky transit periods. Fig. 1 shows the solar power yield of the SME system for July 8th 2018 measured at a 1-second time resolution and time-averaged to 15-minute intervals. The inset shows a period of approximately $50 \mathrm{~min}$ in detail. This is a mostly clear day with a few morning hours of partially clouded conditions, ranging between 0 and 3 oktas as determined by an automated KNMI weatherstation located at a distance of $13 \mathrm{~km}$ (KNMI 2013).

According to the classification scheme described before, this is labelled as a 'mixed conditions' day. It is clear that on a 15-minute interval the absolute value of the highest peaks as well as the amplitude, rate and number of power ramps are lower than on the 1-second interval.

For the inverter limited household PV system distinct plateaus of high values in the high-resolution yield data are observed at 3.2 and $3.0 \mathrm{~kW}$. A time window with two of these steps in detail is shown in Fig. 2. These steps occur after the output power of the solar panels has exceeded the rated power of the inverter. This under-dimensioning of the inverter is commonplace for both household and commercial PV systems, most frequently due to economic reasons. We consider these 


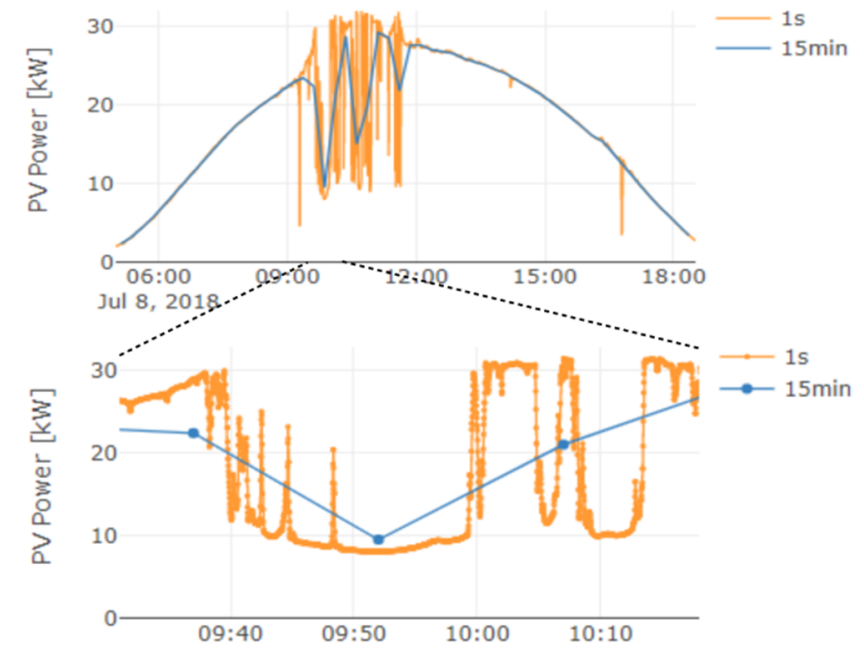

Fig. 1. (a) Example of diurnal cycle of generated PV power of the SME PV system, showing the time-averaging effect of data with a temporal resolution of $1 \mathrm{~s}$ and $15 \mathrm{~min}$, respectively; (b) Detail overview of a $32 \mathrm{~min}$ period. The $1 \mathrm{~s}$ data shows switching between a maximum and minimum state, which is clearly different from the 15-minute data.

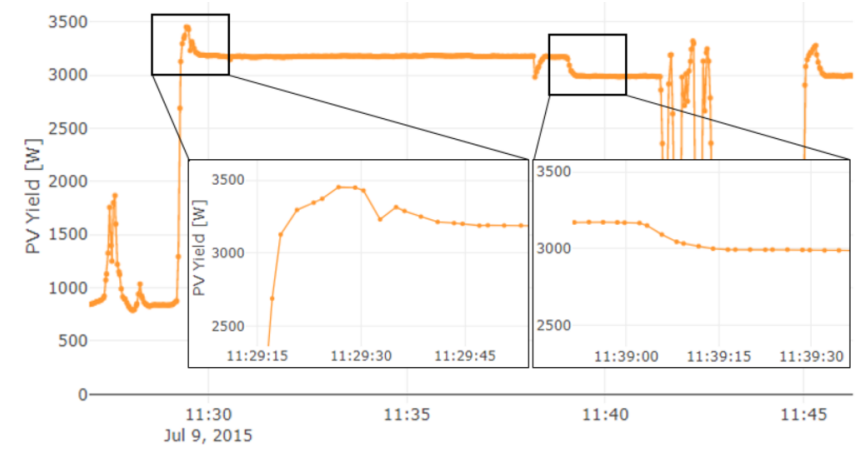

Fig. 2. Detail view of the inverter limited household PV system yield showing distinct step levels. The time between the two subsequent steps is approximately $10 \mathrm{~min}$.

steps to be an artifact since the DC output power of the solar panels exceed the DC rated power of the inverter and not to be caused by meteorological effects. We do include these observations further in our analysis since they impact the effective peak and ramp rate of the system. The combination of downward steps with plateaus of constant high yield are not observed in the other datasets where the inverter rated power is greater than the installed capacity of the solar panels.

\subsection{Classification}

When designing the grid, operators typically perform grid calculations for a selection of extreme cases. In the case of solar energy, days with clear-sky conditions are often assumed to represent the extreme case characterized by the highest values of generated PV power. However, we will quantify to which extent high-frequency fluctuations, not present under clear-sky conditions, can lead to higher stress on the grid in terms of peak power and ramp rate. In order to show this, we categorize each day of each dataset according to the classification scheme used in Section 2.4.

An overview of the days and classes for the SME PV dataset is shown in Fig. 3, while the other datasets showed similar results. This classification result compares well to previous studies (Stein et al., 2012), where the shape is referred to as an 'arrowhead'; due to the absence of days in the region with low variability index and medium surface integral. This is what one would expect; if a day has medium yield, both clear-sky and clouded conditions would have had to occur, meaning variability would have to be non-zero. Moreover we find that the highest peaks only occur on days with partial and high variability of cloudiness.

\subsection{Probability density}

To assess the differences between measurements of the classes, excluding the mixed condition days, and investigate the effect of temporal averaging, we construct the probability density distribution of the raw, high-frequency observations and compare this to the distribution of the 15-minute averages of the same data. In addition to meteorological effects, the diurnal cycle of the sun leads to variability in solar energy. To focus on the meteorological effects, we only consider the time window between 11:00 and 13:00 UTC, which corresponds to the period around solar noon.

In addition to the probability density, kernel density estimates are shown using a Gaussian kernel (Elsinga and van Sark 2017).

\subsubsection{Irradiance}

The probability density function (PDF) of the raw BSRN irradiance measurements at Cabauw and the 15-minute averages is shown in Fig. 4. The measurements clearly show that the highest values of irradiance are observed on days which are categorized as 'highly variable', and not on the days with the highest total yield. On days with high variability, irradiance values exceeding $1200 \mathrm{~W} / \mathrm{m}^{2}$ can be observed, as opposed to approximately $1000 \mathrm{~W} / \mathrm{m}^{2}$ on high yield days. This behavior corresponds to earlier work regarding cloud enhancement (Parzen 1962, Gueymard 2017), where even more extreme cloud enhancement effects were reported. Additionally we find that for highly variable days, the probability density distribution is strongly bimodal while it is unimodal for the high yield and low yield days. This bimodal distribution on highly variable days corresponds to previous research regarding irradiance (Yordanov et al., 2012; Lohmann 2018). An accurate distribution of irradiance is important for solar PV, since many factors in converting irradiance to PV energy are non-linear, e.g. the efficiency of the inverter or resistance losses.

Considering the 15-minute averages, we find that even though the high yield and low yield days strongly correspond to the high resolution observations, the PDF of the highly variable days shows a large discrepancy. Both the effect of cloud enhancement and the bimodality of the distribution are undetectable in the 15-minute time averaged data, complementing previous work on hourly averaged data (Skartveit and Olseth, 1992).

\subsubsection{System comparison}

For all PV systems in this study we observe that the probability density distributions show great similarity to that of irradiance. The highest measured values occur solely on highly variable days, which is again due to enhancement of the irradiance due to the cloud radiation. For this class of days we observe a bimodal distribution of solar power yield at high temporal resolution (Fig. 5). Similar to irradiance, this bimodality is completely lost when averaging the observations to a 15minute interval, see Fig. A1 in appendix.

Moreover, we find that for the inverter-limited system a large number of observations correspond to the rated AC capacity of $2.6 \mathrm{~kW}$. However, especially on highly variable days, the energy output can exceed the capacity significantly.

When considering systems of larger dimensions, a certain level of spatial averaging is to be expected, where the total system is comprised of smaller areas with varying irradiance conditions (Skartveit and Olseth, 1992). Notably, even for the largest system under investigation we find the PDF on highly variable days to be bimodal, which is in agreement with the observation that even for the largest system, the dimensions of clouds are much greater than the size of the system. To a 


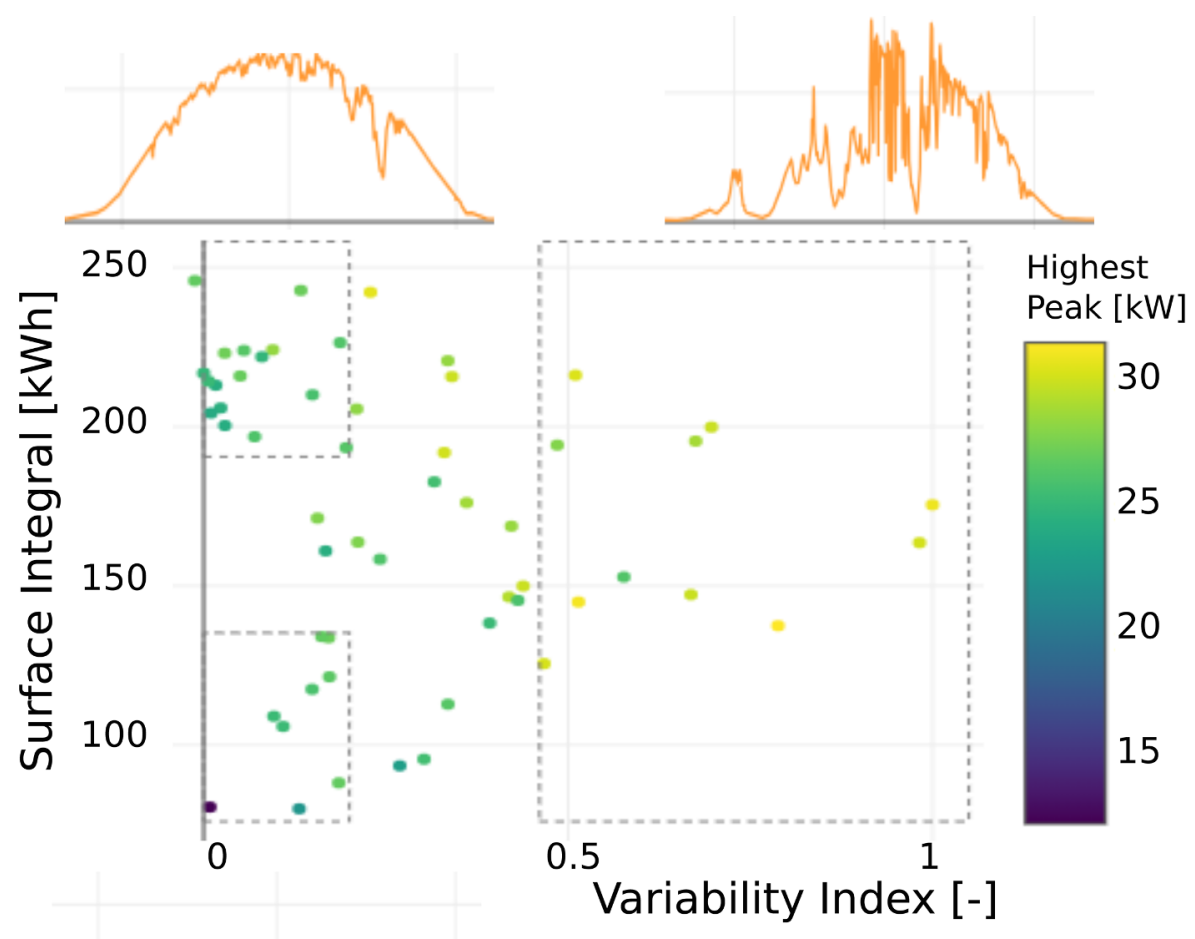

Fig. 3. Classification into 'high yield', 'low yield', 'highly variable' (respectively top left, bottom left, right) of the SME PV system. The color indicates the highest observed power output on the specific day. As a reference, irradiance profiles are depicted for the three mentioned classes.

limited extent, spatial averaging effects can be observed when considering the peak of high yield on highly variable days; this is much wider for the non-limiting household PV system compared to the SME PV system.

If we relate this to grid impact calculations we can state that 15minute averages flatten the extreme values and the probability of 'medium yield' is exaggerated. Additionally, the probability density distribution of PV energy yield closely corresponds to that of irradiance.

\subsubsection{Possible temperature effect}

For the PV household system, we observe the largest difference between the highest values measured at highly variable days compared to high yield days, even larger than observed for the irradiance data. To some extent this could be caused by the higher sampling frequency of the PV measurements compared to the irradiance measurements. However, in Section 3.4 we show that this effect persist when the same

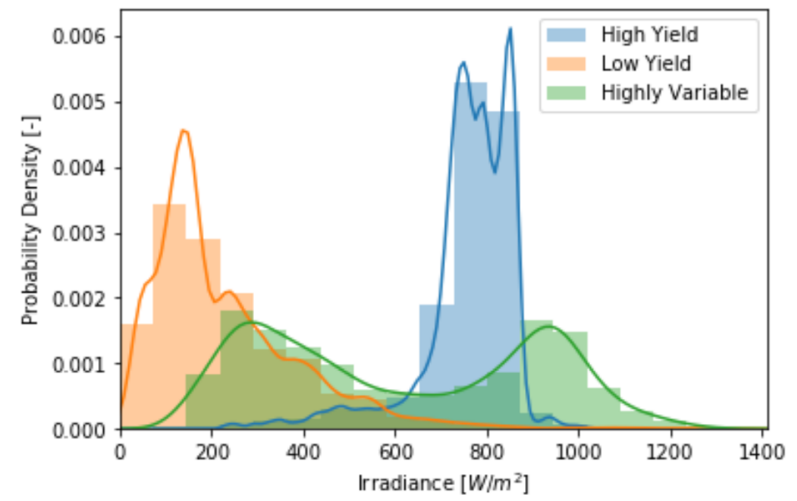

time averaging interval is used.

We hypothesize that in addition to the cloud reflection enhancement, an inverse temperature effect occurs on highly variable days compared to high yield days. The decreasing efficiency of solar cells with increasing cell temperature is well-understood (van Haaren et al., 2014). Shading induced by transient clouds could lead to a lower effective cell temperature resulting in a higher energy output, as the response time of the temperature of the panel is much larger than the ramp rate of irradiance and PV systems themselves are virtually inertia less. The thermal response time of a typical PV panel is reported to be in the order of $7 \mathrm{~min}$ (Skoplaki and Palyvos 2009).

The other PV systems do not show this additional increase in yield. Possibly due to the under dimensioning of the inverter (PV limited system) or spatial averaging effects (PV SME system).

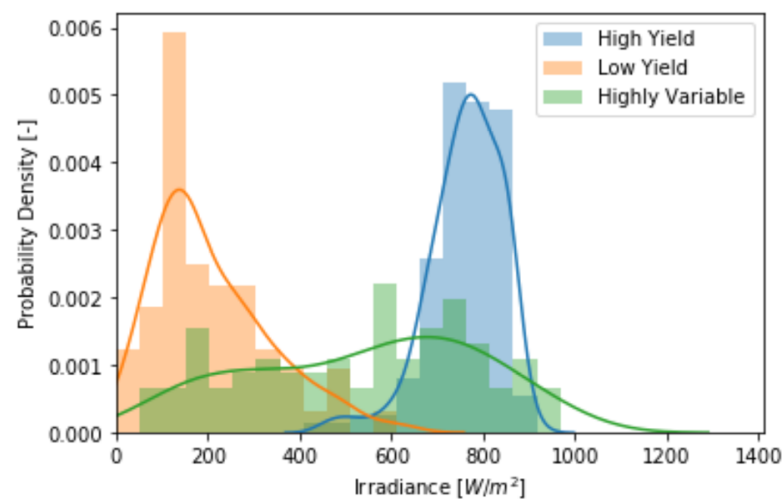

Fig. 4. Probability density (areas) and kernel density estimates (curves) of the measured irradiance at the Cabauw BSRN site at 5-second resolution (left) and 15minute averages (right). Similar results are obtained for PV measurements. 

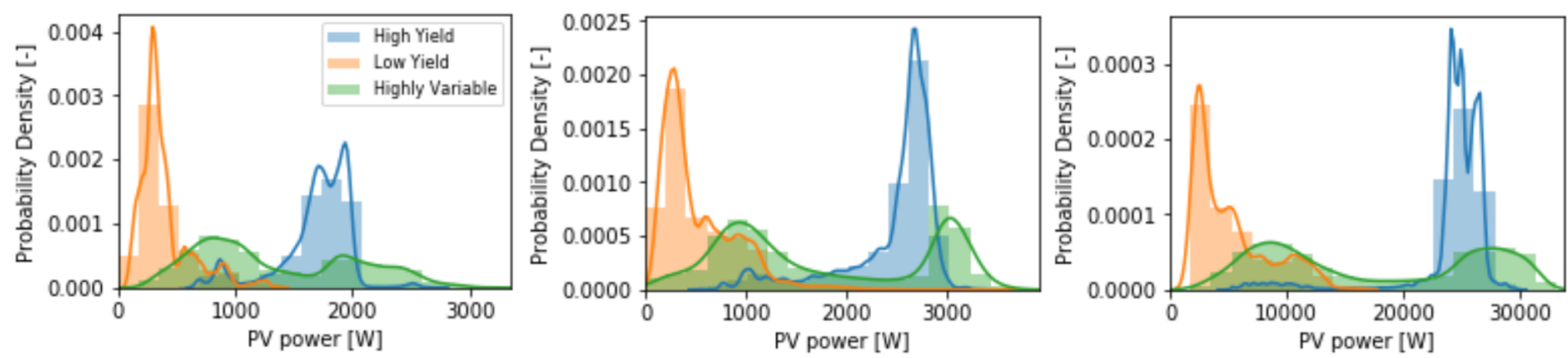

Fig. 5. Probability density distributions of the high-frequency measurements of the PV household (left), PV household with limiting inverter (center) and SME PV system (right).

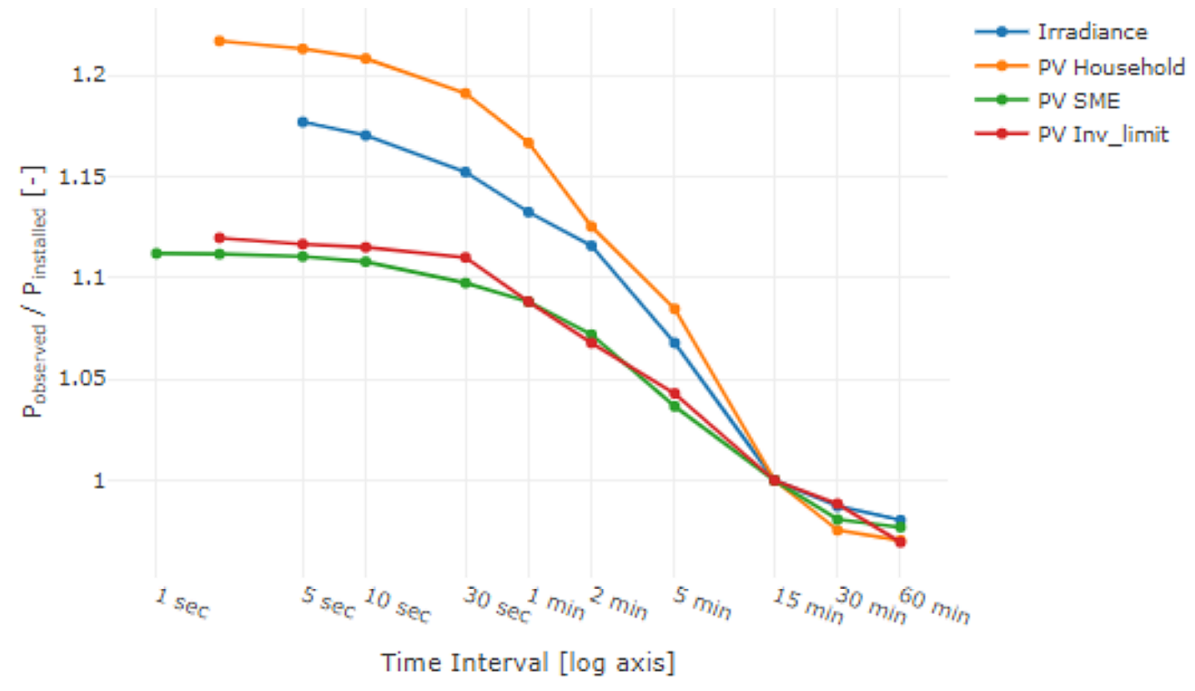

Fig. 6. Overview of peak yield versus time-averaging interval for the four systems under investigation. Surprisingly, the largest effect of temporal averaging is found for the PV household system.

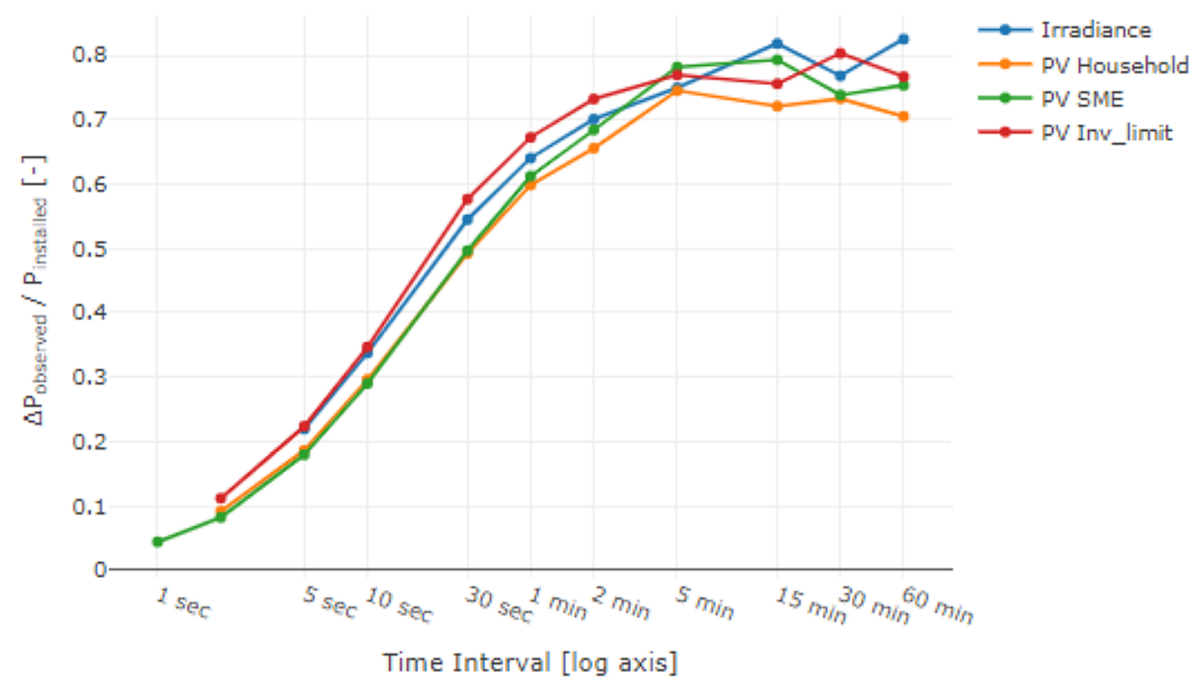

Fig. 7. Overview of highest power ramps between sequential observations for increasing time-averaging interval, relative to the observed maximum peak power at 15 min time-averaging interval.

\subsection{Averaging effect on peak power}

For each of the systems under research, we have determined the peak power observed at a specific time averaging window, normalized to the peak power observed at the time average at $15 \mathrm{~min}$. The results are depicted in Fig. 6.

We find that for the PV household system, the peaks at the 2-second timescale are $22 \%$ higher compared to the 15 -minute average. Notably, this is significantly larger than the increase observed for irradiance: $18 \%$ at 5-second interval. For the SME system, we find that at temporal resolutions of $10 \mathrm{~s}$ or smaller, the increase stabilizes at approximately $11 \%$. We would expect that spatial averaging would lead to smaller increases for larger system sizes. However, this is not observed for the household PV system in Fig. 5. As mentioned before, we conjecture that 
the additional increase of the household system compared to the increase in irradiance is due to temperature effects. For the inverterlimited PV system, the increase is relatively small (12\%). We assume this to be determined by characteristics of the specific inverter such as rated power and efficiency curves.

In the range between $5 \mathrm{~s}$ and $1 \mathrm{~min}$ we still observe significantly higher peak power compared to the 15-minute averages, for all systems under investigation. This suggests that these are the typical timescales of cloud dynamics for which irradiance enhancement can be observed. However, the SME PV system, is insensitive to the increase for time resolutions higher than $10 \mathrm{~s}$, indicating that irradiance enhancement is bound in space in a region typically smaller than the surface area of the SME PV system, which is in the order of $100 \mathrm{~m}^{2}$.

\subsection{Averaging effect on ramp rate}

Fig. 7 shows the power difference between sequential time steps (power ramps) as a function of time averaging interval, normalized to the observed peak power at the 15-minute average, e.g. the same normalization is used as for Fig. 6. All systems under research show a remarkably similar, sigmoid-like increase of normalized ramp rate with increasing time interval, from $\sim 20 \%$ at a 5 -second interval to stabilizing between 70 and $80 \%$ of the observed capacity somewhere between 5 and $15 \mathrm{~min}$. Since even under completely-clouded conditions the PV system still produces energy due to a non-zero diffuse irradiance component, the stabilization at high time scales occurs for a value smaller than 1 .

The observed similarity between the behavior of the systems is counterintuitive to what one might expect in the context of spatial averaging. A large difference in surface area exists between the systems under investigation; the surface area of the household PV systems is in the order of 2000 times the surface area of the pyranometer, and the SME system even in the order of 77,000 . This suggests that the ramp rate is not only determined by the transit time of the cloud edge over the system, but also by the large-scale spatial gradient of the cloud optical depth near the cloud edge. This gradient limits the ramp rate for small systems, where the transit time is in the order of seconds. Additionally, the electrical connection of the PV system may play an important role, since a shaded module can decrease the power of the connected string by more than the peak capacity of the module (Jones and Underwood 2001).

The ramp rate of the inverter-limited system slightly exceeds the other systems under research. We can provide a possible explanation: since the peak output power of the system is limited by the inverter, the observed maximum output power is small compared to the nominal installed capacity of the solar panels. Increases and decreases in output power can therefore be relatively greater than is the case for the nonlimited PV household system. Additionally, the high ramp rate shown in Fig. 7 indicates that the ramp rate is not the limiting factor for the relative small increase in peak power for the inverter limited system shown in Fig. 6.

\section{Discussion and conclusion}

We show that for both irradiance and PV systems typical for small and medium-sized enterprises, 15-minute time averages poorly represent behavior at high temporal resolutions. At small timescales, all systems under research show at highly variable days a bimodal probability density distribution of irradiance or PV power that vanishes under 15-minute averaging. As noted in the introduction, increased PV power output and ramp rates increase the risk of grid voltages exceeding safety limits and threaten the stability of the electricity grid at the local level.

Our findings indicate that the highest PV power measurements do not occur under clear-sky conditions, but under mixed clouds and that this information is completely filtered out at the typically used 15- minute interval. The largest peak power at high time resolution is found for the household PV system at 22\% higher than the 15-minute average. This is even larger than observeable for irradiance (18\%). We conjecture based on results shown in Fig. 6 that in addition to cloud enhancement, temperature related efficiency effects lead to the largest peak power observations of PV systems under mixed-cloud conditions. For the largest system, and the system where the inverter limits the output power, we find maximum power output increases of $11 \%$ and $12 \%$ respectively.

Notably, normalized ramp rates are very similar for all systems under research, ranging from $\sim 20 \%$ at a 5-second interval to stabilizing at $70-80 \%$ between 5 and $10 \mathrm{~min}$. Suggesting large-scale effects such as the gradient of optical thickness near the cloud edge to be dominant over the cloud-transit time over the system.

While it might be unfeasible to calculate the grid load for an entire year using a time step in the order of seconds, the results of this work are relevant to improve the business rules currently used to assess the PV hosting capacity of the electricity grid.

For grid operators, it is commonplace to perform detailed power quality calculations for a selection of 'worst case scenarios'. At present, the 'worst case' for PV is frequently assumed to be the maximum power output under clear sky conditions. However, we observed that the maximum power output of a PV system is up to $22 \%$ higher under mixed-cloud conditions compared to clear sky conditions. Additionally, the largest ramp rates are also found under mixed-cloud conditions. Therefore we strongly recommend to include these situations as well.

Moreover, since the largest fluctuations in power output occur at small time scales and the associated energy yield is very small, readily available power electronics could be included in the design of inverters to mitigate these grid-disturbing effects while only minimally impacting the return on investment of the PV system owner.

In this work we studied temporal averaging effects on power output characteristics of single systems. In practice, grid stability is not threatened by single, smaller systems, but by fleets of systems at distinct grid levels; e.g. low voltage cable (street), secondary substation (neighborhood) and substation (city). While spatial averaging effects have been studied for irradiance, averaging of fluctuations of generated solar power have yet to be quantified directly. As we have shown in this work, power peaks of household PV systems can exceed those observed for irradiance. Possibly due to secondary effects such as an inverse relation between temperature and efficiency, which occur for PV systems but are not present for irradiance. While at present irradiance is frequently studied, future research is required to determine the combined spatio-temporal averaging effects on distributed PV system power output, given the nontrivial relation between irradiance and PV output power.

This work quantifies the commonly observable extremes of output power and ramp rates at very high temporal resolution, in relation to grid stability at the local level. Whether a short-lived extreme of PV power actually causes a grid safety or stability problem depends on many factors such as the properties of the grid components and the instantaneous load profile. Future research could use the relations described in this work to quantify the increased risk in grid instability.

\section{Declaration of Competing Interest}

The authors declare that they have no known competing financial interests or personal relationships that could have appeared to influence the work reported in this paper.

\section{Acknowledgements}

This work is part of the research programme Industrial Doctorates with project number NWA.ID.17.051, which is financed by the Dutch Research Council (NWO), Alliander N.V. and Wageningen University \& Research. 
Chiel van Heerwaarden acknowledges funding from the Dutch Research Council (NWO), project number VI.Vidi.192.068.

The research of L.R. Visser and W.G.J.H.M. van Sark is part of the eNErgy intrAneTs (NEAT) project, which is funded by the Dutch Research Council (NWO) in the framework of the Energy Systems
Integration \& Big Data programme.

The authors acknowledge Hans van der Geest and Koen Verstappen of Alliander N.V. for their guidance in relating fluctuations of solar power to grid stability.

\section{Appendix A}

See Fig. A1.
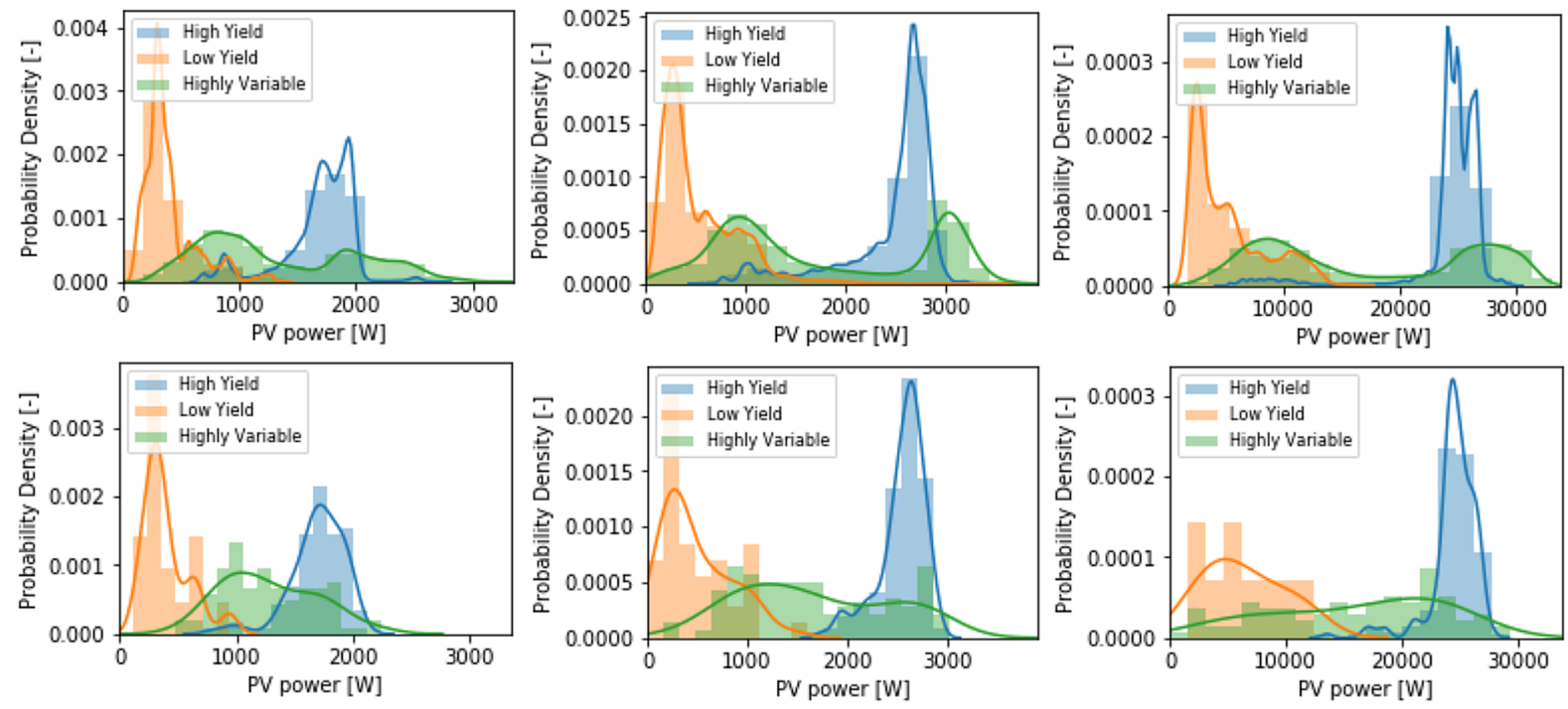

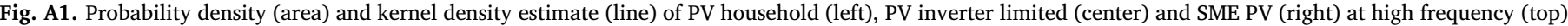

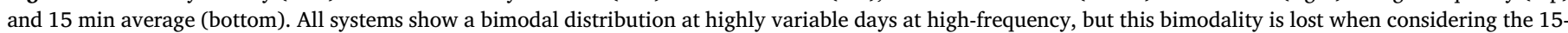
minute averages.

\section{References}

Anvari, M., Lohmann, G., Wächter, M., Milan, P., Lorenz, E., Heinemann, D., Tabar, M.R.R., Peinke, J., 2016. Short term fluctuations of wind and solar power systems. New J. Phys. 18.

Armstrong, S., Hurley, W.G., 2010. A thermal model for photovoltaic panels under varying atmospheric conditions. Appl. Therm. Eng. 30 (11-12), 1488-1495.

Driemel, A., Augustine, J., Behrens, K., Colle, S., Cox, C., Cuevas-Agulló, E., Denn, F.M., et al, 2018. Baseline Surface Radiation Network (BSRN): structure and data description (1992-2017). Earth Syst. Sci. Data 10, 1491-1501.

Elsinga, B., van Sark, W.G.J.H.M., 2017. Short-term peer-to-peer solar forecasting in a network of photovoltaic systems. Appl. Energy 206, 1464-1483.

Gueymard, C.A., 2017. Cloud and albedo enhanceent impacts on solar irradiance using high-frequency measurements from thermopile and photodiode radiometers. Part 1: Impacts on global horizontal irradiance. Sol. Energy 153, 755-765.

van Haaren, Rob, Morjaria, Mahesh, Fthenakis, Vasilis, 2014. Empirical assessment of short-term variability from utility-scale solar PV plants: Assessment of variability from utility-scale solar PV plants. Prog. Photovolt: Res. Appl. 22 (5), 548-559. http:// doi.wiley.com/10.1002/pip.v22.5 http://doi.wiley.com/10.1002/pip.2302https:// doi.org/10.1002/pip.v22.510.1002/pip.2302.

Haegel, N.M., Margolis, R., Buonassisi, T., Feldman, D., Froitzheim, A., Garabedian, R. Green, M., 2017. Terawatt-scale photovoltaics: Trajectories and challenges. Science 356 (6334), 141-143.

Hansen, C.W., Stein, J.S., Riley, D., 2012a. Effect of time scale on analysis of PV system performance. Scandia Report.

Hansen, J.S., Clifford, W., Stein, J., 2012b. Effect of time averaging on estimation of photovoltaic system performance. Sandia National Lab, Albuquerque, NM (United States).

International Renewable Energy Agency, 2019. Renewable Energy Capacity Statistics. IRENA, Abu Dhabi.

Jones, A.D., Underwood, C.P., 2001. A thermal model for photovoltaic systems. Sol. Energy 70 (4), 349-359.

Kipp \& Zonen, n.d. "CMP22, the best Spectrally Flat Class A pyranometer available - Kipp \& Zonen.” Accessed 07 11, 2019. https://www.kippzonen.com/Product/15/CMP22Pyranometer\#.XSb3W-gzaUk.

Kleissl, M., Lave, J., 2013. Cloud speed impact on solar variability scaling - Application to the wavelet variability model. Sol. Energy 91, 11-21.
Knap, W., 2015. KNMI Cabauw Observations. 7 09. Accessed 07 11, 2019. http://projects. knmi.nl/cabauw/bsrn/.

KNMI, 2013. Klimaatdata en -advies, Metadata KNMI-stations, Deelen (06275). 4. Accessed 8 30, 2019. http://projects.knmi.nl/klimatologie/metadata/deelen.html.

LEM, 2014. "lem rt 500." 18 7. Accessed 9 4, 2019. https://www.lem.com/sites/default/ files/products datasheets/rt 500.pdf.

Lobera, D.T., Valkealahti, S., 2013. Dynamic thermal model of solar PV systems under varying climatic conditions. Sol. Energy 93, 183-194.

Lohmann, G.M., 2018. Irradiance Variability Quantification and Small-Scale Averaging in Space and Time: A Short Review. Atmosphere 9 (7), 264-286.

Lohmann, G.M., Monahan, A.H., Heinemann, D., 2016. Local short-term variability in solar irradiance. Atmos. Chem. Phys. 16, 6365-6379.

Lohmann, G.M., Monahan, A.H., 2018. Effects of temporal averaging on short-term irradiance variability under mixed sky conditions. Atmos. Meas. Tech. 11, 3131-3144.

Marcos, J., Marroyo, L., Lorenzo, E., Alvira, D., Izco, E., 2011. Power output fluctuations in large scale PV plants: One year observations with one second resolution and a derived analytic model. Prog. Photovoltaics Res. Appl. 19 (2), 218-227.

Mills, A., Ahlstrom, M., Ellis, A., George, R., Hoff, T., Kroposki, B., 2011. Dark Shadows. IEEE Power Energy Mag. 33-41. https://doi.org/10.1109/MPE.2011.940575.

Parzen, E., 1962. On Estimation of a Probability Density Function and Mode. Ann. Math. Stat. 33 (3), 1065-1076.

Perez, R., Hoff, E.T., 2010. Quantifying PV power Output Variability. Sol. Energy 84, 1782-1793.

Samil Power Co, Ltd., 2016. "Samil Power - Product." Accessed 07 04, 2019. http://www. samilpower.com/uploadfiles/product/SolarRiver\%201100TL\%20-\%201600TL \%20-\%202300TL\%20-\%203000TL\%20-\%203300TL\%20-\%204400TL\%20-\% 205200TL V007AU WEB.pdf.

Sande, P., Danes, M., Dekker, T., 2017. ANDES: grid capacity planning using a bottom-up, profile-based load forecasting approach. CIRED - Open Access Proc. J. 10 (1) 2097-2100.

Shah, R., Mithulananthan, N., Bansal, R.C., Ramachandaramurthy, V.K., 2015. A review of key power system stability challenges for large-scale PV integration. Renew. Sustain. Energy Rev. 1423-1436. https://doi.org/10.1016/j.rser.2014.09.027.

Skartveit, A., Olseth, J.A., 1992. The probability density and autocorrelation of short-term global and beam irradiance. Sol. Energy 49 (6), 477-487.

Skoplaki, E., Palyvos, J.A., 2009. On the temperature dependence of photovoltaic module electrical performance: A review of efficiency/power correlations. Sol. Energy 83 (5), 614-624. 
Stein, J., Hansen, C., Reno, M.J., 2012. The variability index: a new and novel metric for quantifying irradiance and pv output variability. No. SAND2012-2088C.

Stetz, T., von Appen, J., Niedermeyer, F., Scheibner, G., Sikora, R., Braun, M., 2015. Twilight of the grids: The impact of distributed solar on Germany's energy transition 13(2), 50-61.

Suri, M., Huld, T., Dunlop, E., Aluisson, M., Lefevre, M., Wald, L., 2007. Uncertainties in solar electricity yield prediction from fluctuation of solar radiation. In: 22nd European Photovoltaic Solar Energy Conference, Milan, Italy.

Šúri, M., Huld, T.A., Dunlop, E.D., Ossenbrink, H.A., 2017. Potential of solar electricity generation in the European Union member states and candidate countries. Sol. Energy 81 (10), 1295-1305.

Tan, Y.T., Kirschen, D.S., 2007. Impact on the power system of a large penetration of photovoltaic generation. In: IEEE Power Engineering Society General Meeting, pp. 1-8. https://doi.org/10.1109/PES.2007.385563.
Tonkoski, Reinaldo, Lopes, Luiz A.C., 2011. Impact of active power curtailment on overvoltage prevention and energy production of PV inverters connected to low voltage residential feeders. Renewable Energy 3566-3574.

Tsai, H.F., Tsai, H.L., 2012. Implementation and verification of integrated thermal and electrical models for commercial PV modules. Sol. Energy 86, 654-665.

Upp Energy, 2013. Accessed 07 05, 2019. http://www.uppenergy.nl/product/details/1f.

Widén, J., Wäckelgård, E., Paatero, J., Lund, P., 2010. Impacts of distributed photovoltaics on network voltages: Stochastic simulations of three Swedish low-voltage distribution grids. Electr. Power Syst. Res. 80 (12), 1562-1571.

World Meteorological Organization, 2016. International Pyrheliometer Comparison (IPC XII) (28 September - 16 October 2015; Davos, Switzerland). WMO.

Yordanov, G.H., Midgard, O.-M., Saetre, T.O., Nielsen, H.K., Norum, L.E., 2012 Overirradiance (Cloud Enhancement) Events at High Latitudes. IEEE J. Photovolt. 2156-2163. 